УДК 334.02

DOI $10.21661 /$ r- 114200

\title{
А.Ф. Глисин
}

\section{ИТОГИ РАЗВИТИЯ ОСНОВНЫХ СЕКТОРОВ НАУКИ КАК ПРЕДПОСЫЛКИ РЕФОРМИРОВАНИЯ РОССИЙСКИХ АКАДЕМИЙ НАУК}

Аннотация: в предлагаемой статье автор проводит анализ состояния и развития основных секторов науки России в период, предшествовавший началу проведения глобальных реформ в данной области, в частности реформьл РАН и ее региональных отделений, а также отраслевых академий наук. Выбор академической науки в качестве индикатора состояния научной сферы России не случаен, так как результаты работы организаций именно данного сектора в основном формируют и развивают систему фундаментальных знаний, определяющуих конщептуальные направления развития научной мысли и воздействующих на прикладную науку, разработки и инновации, тем самым определяя развитие экономики и сочуиальной сферы страныл. В этой связи в работе анализируются тенденциии развития академической науки во взаимосвязи с общуими тенденциями развития научной деятельности в стране с изелью обоснования необходимости проведения реформ научного сектора. При этом в качестве информачионной базы использовались официильные статистические данные. По результатам исследований автором определены проблемные зоны развития отечественной науки, обуславливающие цуелесообразность осущуествления реформ для ее дальнейшего поступательного развития и повышения уровня эффективности.

Ключевые слова: научная деятельность, фундаментальная наука, прикладные исследования, Российская академия наук, академический сектор, государственный сектор экономики, научно-исследовательские организации, кадровый потенциил науки, затраты на исследования, разработки, эффективность научных исследований. 


\section{A.F. Glisin}

\section{THE DEVELOPMENT OF THE MAIN SECTORS OF RUSSIAN SCIENCE IN THE PRE-REFORM PERIOD OF RAS}

Abstract: in this article the author analyzes the state and development of the main sectors of Russian science in the period preceding the beginning of the global reform in this area, in particular, reform of the RAS and its regional offices, and branch academies of sciences. Selection of academic science as an indicator of the state of scientific sphere Russia is not accidental, since the results of the companies is this sector is mainly formed and developed a system of fundamental knowledge, defining the conceptual directions of development of scientific thought and acting on applied science, development and innovation, the thus determining the development of the economy and social sphere. In this regard, the paper analyzes trends in the development of academic science in relation to the general trends of development of scientific activity in the country in order to justify the need for reform of the scientific sector. As the information base used the official statistics. According to the research the author defines the problem areas of domestic science, causing the feasibility of reforms for further sustainable development and improving efficiency

Keywords: science, basic science, applied research, The Russian Academy of Sciences, the academic sector, the public sector, research organizations, human resources potential of science, the costs of research, development, the effectiveness of research.

Сложившаяся на современном этапе система международных рыночных отношений, по оценкам специалистов, свидетельствует о том, что поступательное развитие национальных экономик во многом обусловлено уровнем развития производительных сил и производственных отношений, основанных на достижениях науки, техники и технологий, которые позволяют поддерживать и развивать соответствующие социальные стандарты и высокий уровень жизни людей. В этой связи задачи поддержания высоких темпов развития науки стоят перед всеми государствами, однако, не многие из них могут позволить себе обеспечить 
соответствующий уровень проведения как фундаментальных исследований, так и прикладных исследований, и разработок [1, с. 93].

Это обусловлено в значительной мере отсутствием или недостаточным развитием кадрового и технологического потенциалов, необходимых для эффективной научной деятельности. Наша страна в течении многих лет была одним из лидеров в развитии науки, однако длительный период экономической стагнации обусловил значительное падение общего уровня развития научной деятельности, ее технической базы и кадрового потенциала.

В последние годы с ростом финансирования науки наблюдается постепенное возвращение утраченных позиций нашей страной в научной и инновационной сферах, что могло бы послужить предпосылкой для повышения эффективности экономики и социальной сферы, улучшения положения страны на мировой арене [2, с. 37]. Однако на практике существенного влияния на экономическое развитие страны рост финансирования науки в силу ряда причин не произвел. Поэтому требуется более масштабная реорганизация научно - технической деятельности, направленная на повышение ее результативности и прежде всего в системе организаций РАН, обеспечивающих развитие фундаментальной науки.

Особое положение академического сектора науки определяется его главной задачей, которая состоит в обеспечении высокого уровня фундаментальных исследований, а также решении научных задач, определяемых государством в качестве приоритетных [3, с. 3-4].

Помимо РАН и ее региональных отделений, в академический сектор науки в предреформенный период входили отраслевые академии: Российская академия сельскохозяйственных наук (РАСХН), Российская академия медицинских наук (PAMH), Российская академия архитектуры и строительных наук (РАACH), Российская академия образования (PAO) и Российская академия художеств (PAX).

Результаты работы организаций академической науки коренным образом воздействуют на прикладную науку, разработки и инновации, что в конечном 
счете определяет ее значимость для развития науки страны в целом и воздействие на экономику и социальную сферу.

Рассмотрим основные тенденции деятельности академического сектора науки в годы, предшествующие его реорганизации, поскольку о целесообразности и результативности осуществляемых реформ академической науки имеются различные, порой, прямо противоположные точки зрения.

Согласно статистическим данным [3, с. 34], государственная система академий наук в предреформенном 2013 году включала 872 научные организации, что составляло $34,2 \%$ от числа государственных научных организаций или 24,2\% от общего числа научных организаций Российской Федерации. Общая численность организаций, занятых наукой в системе государственных академий, увеличилась за период с 2000 г. по 2013 г. почти на 5,0\%. Отмеченное увеличение числа научных организаций происходило на фоне сокращения числа научных организаций неакадемического сектора - на 16,4\%. Это в определенной мере свидетельствует о возрастании роли фундаментальных исследований в решении задач научнотехнологического развития страны и совершенствовании организационной структуры научных организаций.

Однако, одновременно с ростом числа научных организаций в рассматриваемом периоде происходило сокращение численности персонала, занятого в академическом секторе. Так, численность персонала, занятого научными исследованиями и разработками в академическом секторе к 2013 г., сократилась относительно 2000 г. почти на 10,0\% и составила 132,4 тыс. чел. Вместе с тем следует признать, что сокращение научного персонала в академическом секторе было значительно меньшим, чем по научным организациям, не относящимся к структуре академий $-19,7 \%$.

Численность персонала, занятого непосредственно в Российской академии наук и её региональных отделениях в 2013г., составляла 97,6 тыс. чел., или 13,4\% общей численности научного персонала страны. Сокращение персонала, занятого научными исследованиями, происходило как в организациях РАН, так и в 
отраслевых академиях наук, что отрицательно сказалось в целом на развитии фундаментальных исследований и их результативности.

Важную роль в решении задач фундаментальной научной деятельности выполняют исследователи высшей квалификации - доктора и кандидаты наук. В системе государственных академий наук по состоянию на 2013 г. научную работу вели более 14,1 тыс. докторов наук и 32.6 тыс. кандидатов наук, что составляло, соответственно, 51,6\% и 40,4\% от их общей численности по Российской Федерации. Более $76 \%$ исследователей с учеными степенями докторов и кандидатов наук осуществляли свою научную деятельность непосредственно в организациях Российской академии наук и ее региональных отделениях. На первый взгляд, приведенные данные свидетельствуют о достаточно высоком уровне кадрового потенциала академических организаций в период, предшествующий реформе РАН.

Между тем, согласно имеющимся данным [3, с. 54], за период 2000-2013 гг. наиболее высоким прирост численности ученых со степенью доктора наук был в научных организациях, не входящих в систему государственных академий наук, составивший почти 39,7\%. В РАН и её региональных отделениях прирост ровнялся $15,7 \%$, а в отраслевых академиях наук - 9,3\%.

Таким образом, темпы роста численности научных специалистов РАН со степенью доктора наук в годы, предшествующие ее реорганизации, были существенно ниже, чем в других секторах научной деятельности, что отрицательно сказывалось на качестве фундаментальных исследований и развитии научно технической деятельности в стране в целом.

Одновременно, в рассматриваемом периоде значительно сократилась в организациях системы госакадемий численность научных работников, имеющих степень кандидата наук - на 6,6\%, в том числе по РАН и её отделениям - на 3,5\%, а в отраслевых академиях наук - на 15,3\%.

Сокращение численности докторов и кандидатов наук в академическом секторе отрицательно влияло на качество фундаментальных научных исследований 
и масштабы использования их результатов как в прикладной науке, так и народном хозяйстве в целом.

Структура научных кадров госакадемий в разрезе основных областей научных знаний в течении 2000-2013 гг. оставалась почти без изменений и недостаточно учитывала возникновение новых направлений исследований [4]. Так, доля исследователей в области естественных наук сохранялась, примерно, на уровне $56 \%$, сельскохозяйственных наук - 12\%, технических наук - $11 \%$, медицинских $-7 \%$, гуманитарных - 6\% и общественных наук $-6 \%$.

Важной характеристикой качества научных кадров является их возрастной состав. В последние годы в государственном академическом секторе науки, согласно статистическим данным, усилилась негативная тенденция увеличения числа лиц в возрасте 70 лет и старше. Их доля в общей численности научных работников выросла с 4,6\% в 2010 г. до 14,3\% в 2013 г. Одновременно сократилась доля ученых в наиболее трудоспособном возрасте 30-49 лет с 43,2\% до $32,7 \%$, а в возрасте 50-59 лет- соответственно, с 24,2\% до 19,9\%. Данная тенденция отрицательно сказывалась на качестве исследований, проводимых научными организациями РАН, в том числе по новым приоритетным направлениям науки.

Следует отметить, что имели место и некоторые положительные тенденции в формировании кадрового потенциала академической науки, но они не могли компенсировать отмеченные недостатки. В частности, увеличился приток в научные организации РАН молодых исследователей в возрасте до 29 лет. Их доля в общей численности исследователей возросла за период 2000-2013 гг. с 10,0\% до 13,7\%. Однако, указанный рост доли молодых научных кадров оказался недостаточным, чтобы существенно улучшить возрастную структуру исследователей в академическом секторе. В результате средний возраст исследователей в системе государственных академий наук по состоянию на конец 2013 г. составил 
50 лет. Это на 6 лет превышает средний возраст исследователей в неакадемическом секторе науки. Сложившаяся ситуация с возрастным составом научных кадров в системе РАН требовала принятия эффективных решений в данной области.

Пополнение научных кадров молодыми исследователями напрямую связано с их подготовкой в аспирантуре. Однако, как свидетельствуют статистические данные, в системе РАН с решением этой задачи в рассматриваемом периоде не все обстояло однозначно [3, с. 8-9; с. 90-101].

Так, количество аспирантов в академическом секторе за период 20002013 гг. уменьшилось почти на 24,0\%. Хотя, в организациях, не входящих в систему государственных академий, их численность за тот же период наоборот увеличилась более чем на $15 \%$. Одновременно наметилось сокращение приема в аспирантуру в организациях государственных академий наук

Сложился также относительно невысокий уровень выпуска аспирантов с защитой диссертаций. Так, доля выпуска аспирантов с защитой диссертации, в общей численности выпуска из аспирантуры в организациях академического сектора науки в 2013 г. составила всего 17,0\%, в то время, как в научных организациях, не входящих в систему госакадемий, этот показатель ровнялся $26,5 \%$. При этом, численность защитившихся аспирантов за период 2000-2013 гг.в научных организациях академического сектора сократилась на 3,8\%. Таким образом, приведенные данные о подготовке научных кадров в академическом секторе науки через аспирантуру свидетельствуют о недостатках в организации этой работы.

Еще более острой оказалась проблема подготовки докторов наук. Общая численность докторантов в академическом секторе науки по итогам 2013 г. составила 183 человека (4,0\% от общей численности в целом по Российской Федерации). Их количество, начиная с 2004 года, постоянно сокращалось. При росте численности докторантов в целом по Российской Федерации за период 20002013 гг. на 8,5\%, в научных организациях, неакадемического сектора, - на 14,0\%, их число в академическом секторе науки сократилось почти в 2 раза. Отчасти это 
обусловлено тем, что в академическом секторе резко сократился прием в докторантуру (почти в 2 раза). Все это отрицательно сказалось на подготовке молодых докторов наук в организациях академий наук.

Выпуск докторантов в целом по Российской федерации за данный период также сократился, но не на столько сильно, как в академическом секторе (за период 2000-2013 гг. снижение составило 25,4\%). Одновременно сократился, выпуск докторантов с защитой диссертаций. Если в целом по России он уменьшился примерно в 1,5 раза, то по академическому сектору науки - почти в 6 раз.

Приведенные статистические данные свидетельствуют о резком снижении роли академического сектора науки в подготовке молодых научных кадров высшей квалификации в предреформенный период. Это обстоятельство, в свою очередь, отрицательно сказывается на результативности фундаментальных научных исследований, их влиянии на эффективность науки в целом.

Что касается материально-технической базы организаций академического сектора науки, то в количественном отношении она весьма существенна, и составляет около четверти всего объема основных средств организаций, выполняющих научные исследования и разработки в России. Стоимость основных средств, задействованных в проведении научных исследований и разработок организациями государственных академий наук по итогам 2013 г. оценивалась в 249,2 млрд руб. За период 2000-2013 гг. фондовооруженность научных организаций государственных академий наук в сопоставимых ценах возросла в 1,6 раза [3, с. 32, 238, 242-243]. Еще больше увеличилась за тот же период техническая вооруженность проводимых научных исследований - в 2,7 раза. Рост данных показателей в целом по научным организациям в стране был несколько ниже и составил, соответственно, 1,2 раза и 1,9 раза. 
Следует, однако, отметить, что в качественном отношении материальнотехническая база организаций академий наук, по оценкам специалистов, не всегда развивалась достаточно интенсивно и не в полной мере соответствует потребностям проводимых фундаментальных исследований, особенно по приоритетным направлениям развития науки, и нуждается в дальнейшем обновлении.

Результаты фундаментальных исследований, осуществляемых в академическом секторе науки, находят свое дальнейшее использование в прикладных исследованиях, разработках, инновационной и социально - экономической деятельности. В этой связи важно выявить отражают ли имевшиеся негативные тенденции развития академического сектора науки тенденции развития научной, научно - технической, технологической, инновационной и социально - экономической деятельности в стране в целом.

С этой целью рассмотрим некоторые показатели развития научной и инновационной деятельности в стране в рассматриваемом периоде. Основной удельный вес среди организаций, занимающихся научной деятельностью в стране, составляют организации государственного сектора экономики. Для анализа его состояния и уровня развития используем соответствующую статистическую информацию [12].

Государственный сектор экономики России включает [6, с. 5; 7, с. 2] в себя государственные унитарные предприятия, в том числе казенные; государственные учреждения; хозяйственные общества, в уставном капитале которых более 50 процентов акций (долей) находятся в государственной собственности; хозяйственные общества, в уставном капитале которых более 50 процентов акций (долей) находятся в собственности хозяйственных обществ, относящихся к государственному сектору экономики.

В качестве статистических показателей, характеризующих развитие организаций государственного сектора экономики, занимающихся научными исследованиями и разработками в Российской Федерации, используем, в основном, те 
же показатели, что и для анализа развития академического сектора науки. Это количество организаций, выполняющих научные исследования; численность персонала, непосредственно занятого исследованиями и разработками; внутренние затраты на исследования и разработки; среднегодовая стоимость основных средств, используемых для проведения исследований и разработок [12, с. 8].

Ниже представлена динамика основных показателей развития государственных организаций, занимающихся научными исследованиями и разработками в России, за период 2005-2013 гг.

\section{Количество организаций, осуществляющих исследования и разработки}

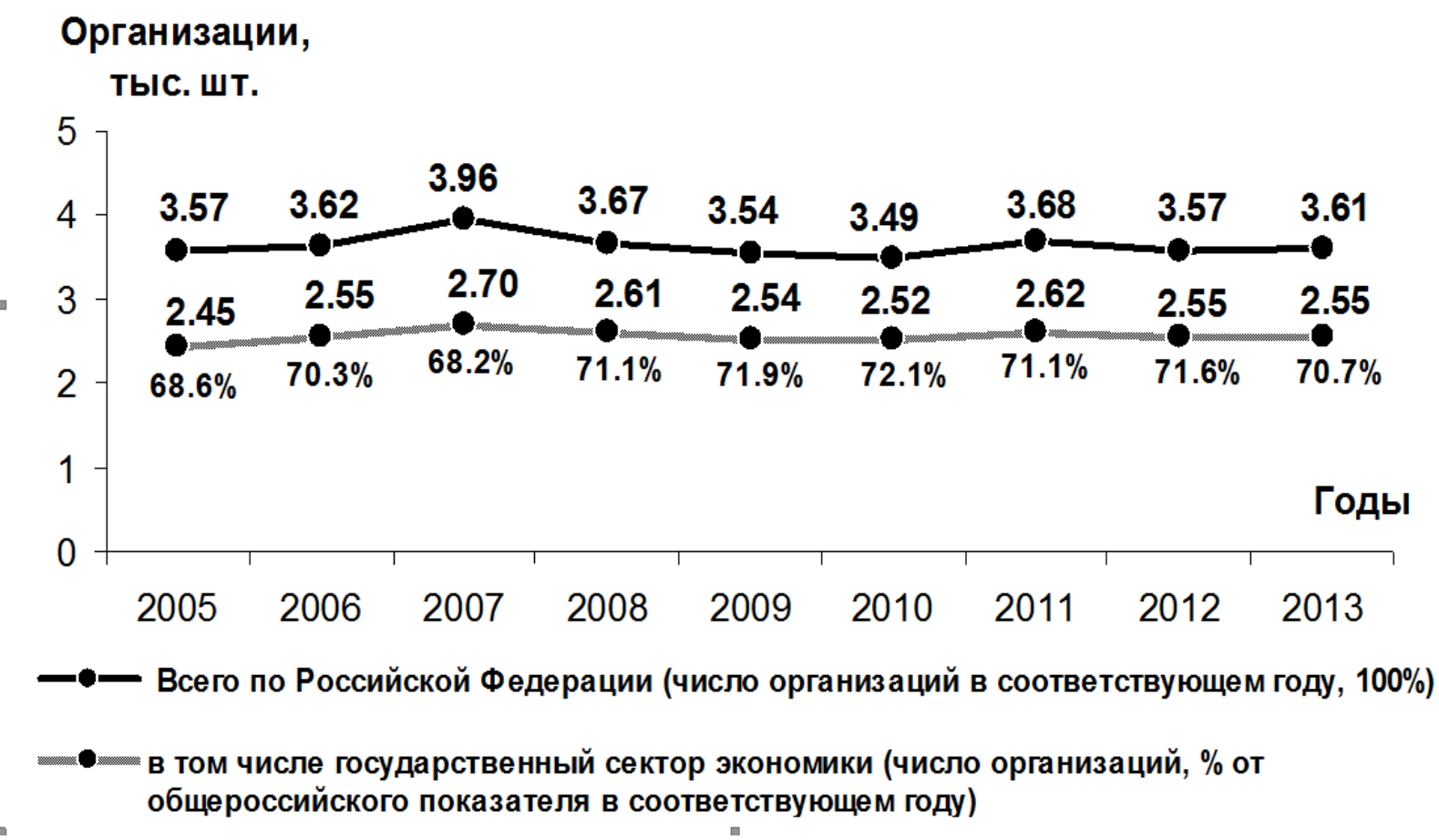

Рис. 1

Источник: составлено автором по данным официальных сайтов ГБНУ НИИ РИНКЦЭ: http://www-old.extech.ru/, http://csrs.ru/ 
Численность персонала организаций, занятого исследованиями и разработками

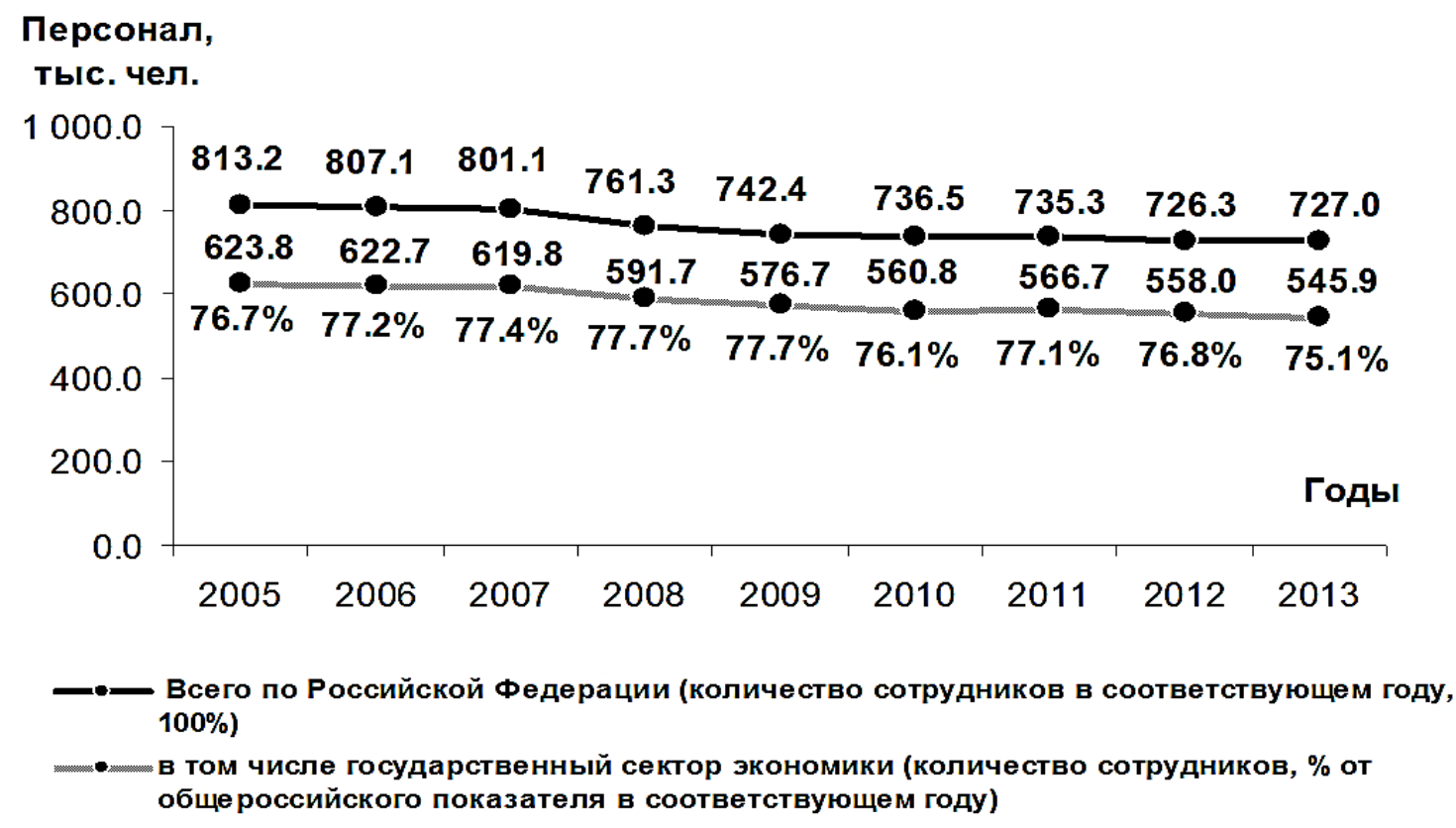

Рис. 2

Источник: составлено автором по даннылм официальных сайтов ФГБНУ НИИ РИНКЦЭ: http://www-old.extech.ru/, http://csrs.ru/

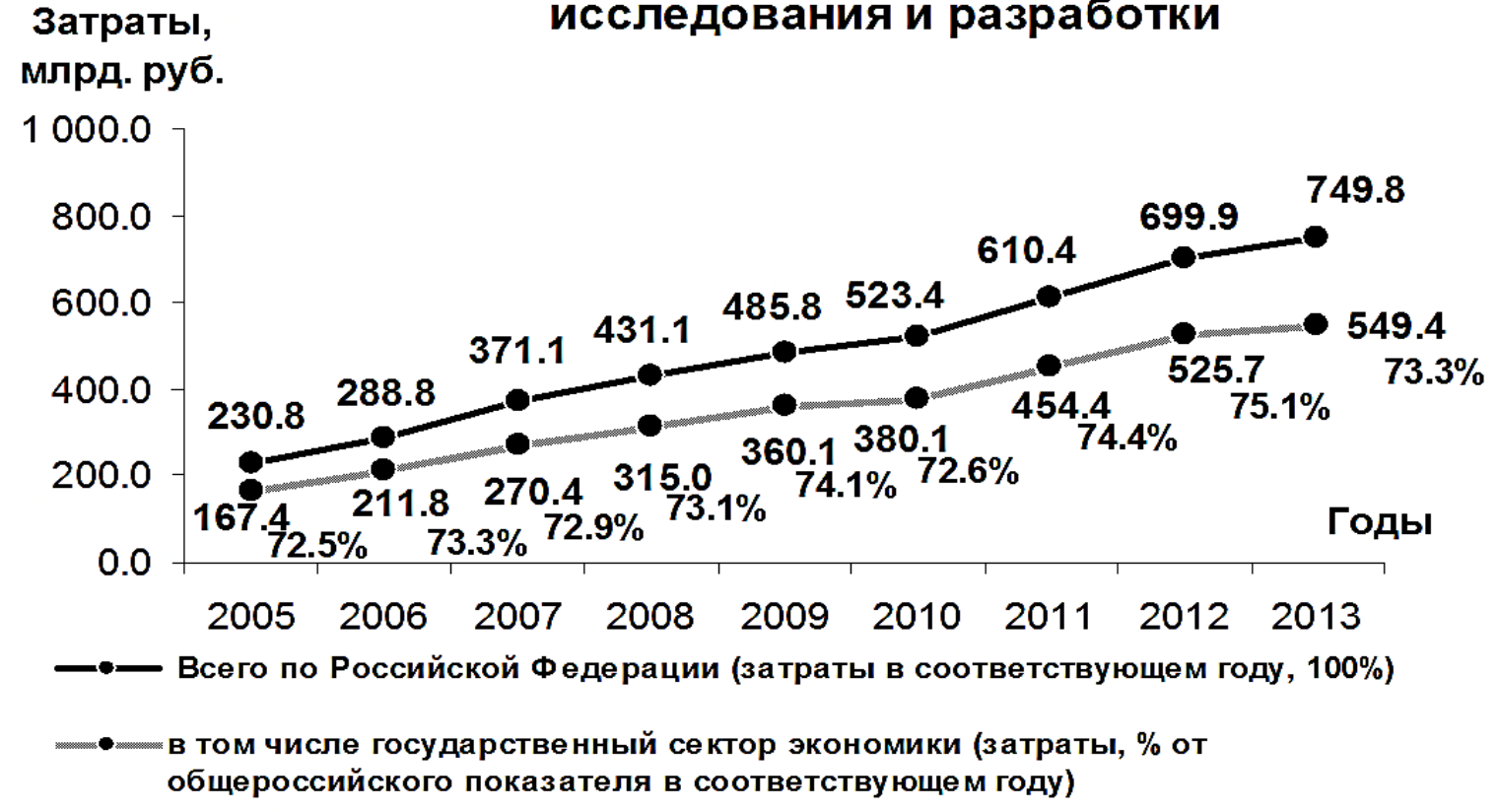

\section{Внутренние затраты организаций на исследования и разработки} млрд. руб.

Рис. 3

Источник: составлено автором по данным офищиальных сайтов ФГБНУ НИИ РИНКЦЭ: http://www-old.extech.ru/, http://csrs.ru/ 
млрд. руб.

Среднегодовая стоимость основных средств

организаций

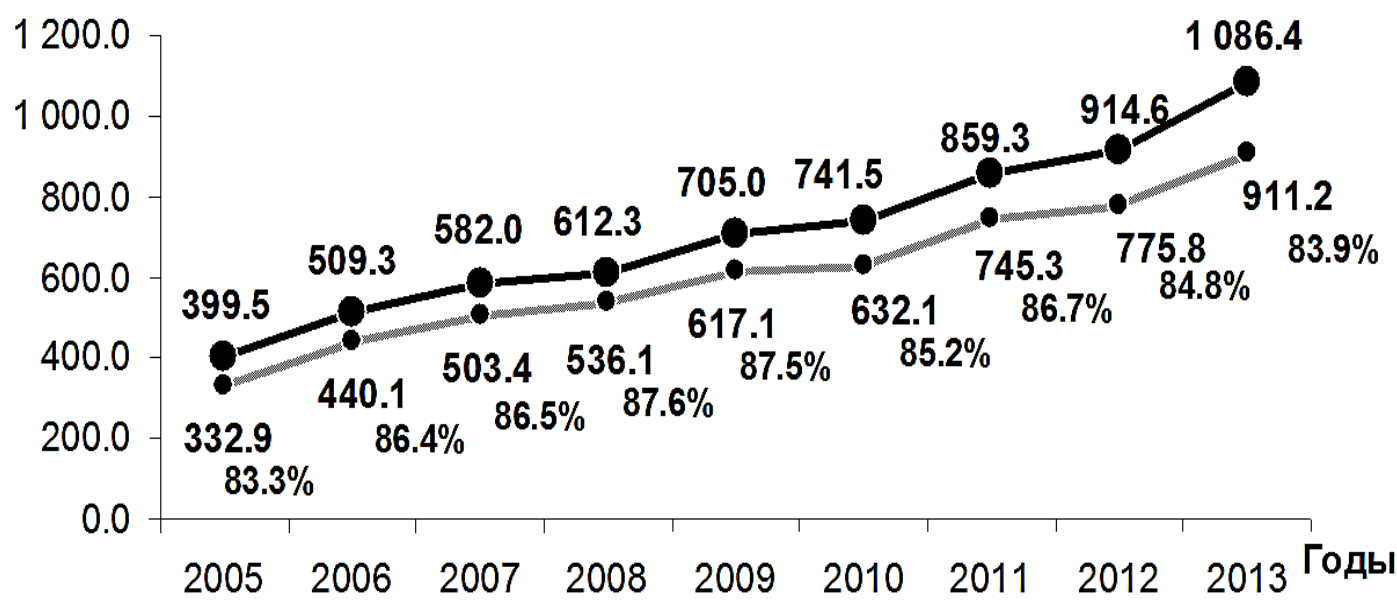

——Всего по Российской Федерации (стоимость ОС в соответствующем году, 100\%)

_- в том числе государственный сектор экономики (стоимость ОС, \% от общероссийского показателя в соответствующем году)

Рис. 4

Источник: составлено автором по данным официальных сайтов ФГБНУ НИИ РИНКЦЭ: http://www-old.extech.ru/, http://csrs.ru/

Приведенные на графиках статистические данные показывают, что именно в государственном секторе сосредоточено, по состоянию на конец 2013 г., порядка 70,0-75,0\% числа научных организаций, численности занятого в них персонала, внутренних затрат на исследования и разработки в России. А в части объемов, используемых в науке (непосредственно для исследований и разработок) основных средств, государственному сектору принадлежит более $83,0 \%$ их общей стоимости. Таким образом, можно предположить, что тенденции развития науки государственного сектора экономики в основном отражают тенденции развития науки России в целом.

За рассматриваемый период 2005-2013 гг. количество научных организаций, входящих в государственный сектор экономики, увеличилось на 4,1\%. Одновременно наблюдался рост внутренних затрат на исследования и разработки, который в рассматриваемом периоде составил (в сопоставимых ценах 2005 г.) 
38,0\%, а среднегодовая стоимость основных средств (в сопоставимых ценах 2005 г.) увеличилась на 21,6\%. Данная информация свидетельствуют о том, что тенденции развития научных организаций государственного сектора экономики в рассматриваемом периоде были близки отмеченным ранее тенденциям развития организаций академического сектора науки, что указывает на их значительную взаимосвязь.

Негативной тенденцией, характеризующей в целом отечественную науку в рассматриваемом периоде, стало сокращение, как и в академическом секторе, кадрового потенциала. Так, численность персонала, занятого исследованиями и разработками в организациях государственного сектора экономики, уменьшилась более чем на $12,5 \%$ [12, с. 7-10].

В течение всего рассматриваемого периода наблюдалась тенденция преобладания государственных научных учреждений в общей структуре государственных субъектов хозяйствования, осуществляющих научные исследования и разработки. На протяжении 2005-2013 гг. доля этих учреждений была на уровне 6062\%. В тоже время доля государственных унитарных предприятий, ведущих активную научную работу, снизилась за этот период с 28,0\% до 8,0\%.

Обращает на себя внимание неравномерность распределения научных организаций по территории Российской Федерации. В периоде 2005-2013 гг., сохранялось преобладание основной массы организаций в Центральном федеральном округе, где было сконцентрировано по состоянию на конец 2013 г. порядка 35,0\% научных учреждений и более половины $(50,5 \%)$ численности всего персонала, занятого исследованиями и разработками.

Значительную долю в этих показателях занимает Москва, где сконцентрировано почти 20,0\% всех научных организаций и 35,0\% занятого в них персонала. На втором месте находится Приволжский федеральный округ, составивший по числу организаций, вовлеченных в научную деятельность 15,5\%, а по 
численности персонала 14,1\%. Следующее место занимает Северо-Западный федеральный округ и город Санкт-Петербург, в которых показатель количества организаций составил 13,0\% и 7,9\%, а численность задействованного персонала$13,3 \%$ и $10,6 \%$, соответственно.

Схож по данным характеристикам с Северо-Западным округом Сибирский федеральный округ, составляя в рассматриваемых показателях - 13,4\% и 8,6\%, соответственно. Что касается прочих регионов, то, например, в Южном федеральном округе анализируемые показатели составляют уже более низкую долю 6,9\% по численности организаций и 3,8\% по персоналу, в Уральском - 6,5\% и $6,3 \%$, соответственно, Дальневосточном - 6,3\% и 2,4\%, а в Северо-Кавказском всего 3,8\% и 1,0\%. Приведенное территориальное распределение научных организаций в значительной мере соответствует распределению организаций академического сектора науки и нуждается, вероятно, в более равномерном и согласованном распределении по округам и регионам страны.

Важным показателем, отражающим базовые параметры для эффективной научной работы, выступает объем внутренних затрат на научные исследования и разработки. Наиболее высокий показатель внутренних затрат на научные исследования в Центральном федеральном округе, где сосредоточено более половины финансовых средств на исследования и разработки $(52,0 \%)$, основная часть которых $(37,8 \%)$ приходится на организации Москвы.

В современных российских экономический условиях, как, впрочем, и во всем мире, одним из важнейших вопросов, стоящих перед исследовательскими организациями и компаниями, занимающимися какими-либо научными исследованиями, разработками и наукоемкими технологиями, является вопрос об источниках финансирования. Рассматривая научные организации государственного сектора, мы говорим в первую очередь о финансовых потоках, исходящих от государства. Однако в условиях рыночной экономики, все большую значимость 
должны приобретать негосударственные источники финансирования науки. Ситуация последних лет диктует необходимость формирования комплексного финансирования науки как из бюджетных источников, так и из средств организаций негосударственного сектора экономики, а также денежных потоков, образуемых коммерческой деятельностью самих исследовательских организаций. При этом характер коммерциализации науки остается весьма дискуссионным, так как наряду с удовлетворением рыночного спроса на определенные категории научных разработок, отражающих, как правило, прикладную часть науки, существует и необходимость продвижения в области фундаментальных знаний, требующая более длительных сроков на реализацию и не всегда сопряженная с текущими потребностями бизнеса и уровнем развития технологий.

В настоящее время ситуация с финансированием науки в организациях государственного сектора экономики складывается следующим образом [12, с. 21$].$

Как показывают данные приведенного ниже графика (рис. 5), средства бюджетов продолжают оставаться основным источником финансирования исследований и разработок в России, а их доля и объемы в общей структуре средств, направляемых на науку, имеют тенденцию к росту. Так, в 2005г. удельный вес средств бюджета в финансировании внутренних затрат на исследования и разработки в госсекторе составлял 70,8\%, а в 2013 г. он увеличился до 72,8\%. При этом, в Москве данный показатель вырос за период 2005-2013 гг. с 66,8\% до $76,2 \%$. 


\section{Внутренние затраты организаций государственного сектора экономики на научные исследования и разработки по источникам финанс ирования}

млрд. руб.

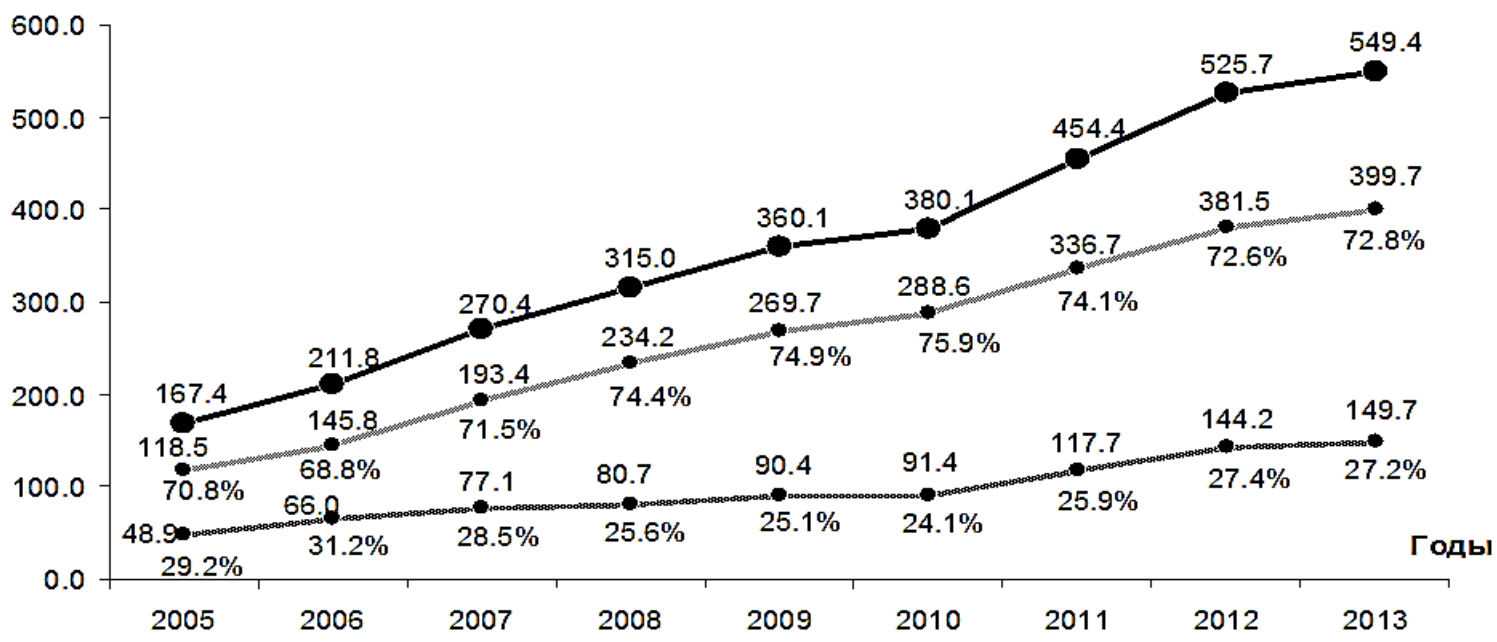

-•-Всего у организаций госсектора по Российской Федерации (Вн. Затраты в соответствующем году, $100 \%)$

- в том чис ле средства бюджетов (Вн. Затраты, \% от общероссийского показателя по госсектору в соответствующем году)

Рис. 5

Источник: составлено автором по даннылм официальныхх сайтов ФГБНУ НИИ РИНКЦЭ: http://www-old.extech.ru/, http://csrs.ru/

В тоже время, в рассматриваемом периоде наблюдалась тенденция достаточно активного привлечения рядом государственных научных организаций внебюджетных источников финансирования. Однако, как в абсолютном, так и в относительном выражении негосударственное финансирование науки увеличивалось более низкими темпами, чем государственное, что фактически не оказывает существенного влияния на совершенствование структуры затрат на научные исследования и разработки.

Примерами наиболее активного привлечения внебюджетных источников финансирования, в региональном разрезе могут служить организации Приволжского федерального округа, где доля негосударственных финансовых источников внутренних затрат научных организаций выросла с 24,3\% в 2005 г. до 32,7\% в 2013 г., т.е. на 8,4 п. п. Аналогичная картина имеет место в Северо-Западном, 
Северо-Кавказском и Уральском федеральных округах [12, с. 31-35]. Однако эти примеры имеют пока немассовый характер и нуждаются в более широком распространении.

Важной характеристикой развития науки являются источники и соотношения роста внутренних текущих затрат на фундаментальные и прикладные исследования.

млрд.руб.

\section{Внутренние текущие затраты на фундаментальные и прикладные исследования и разработки организаций}

600 государственного сектора экономики

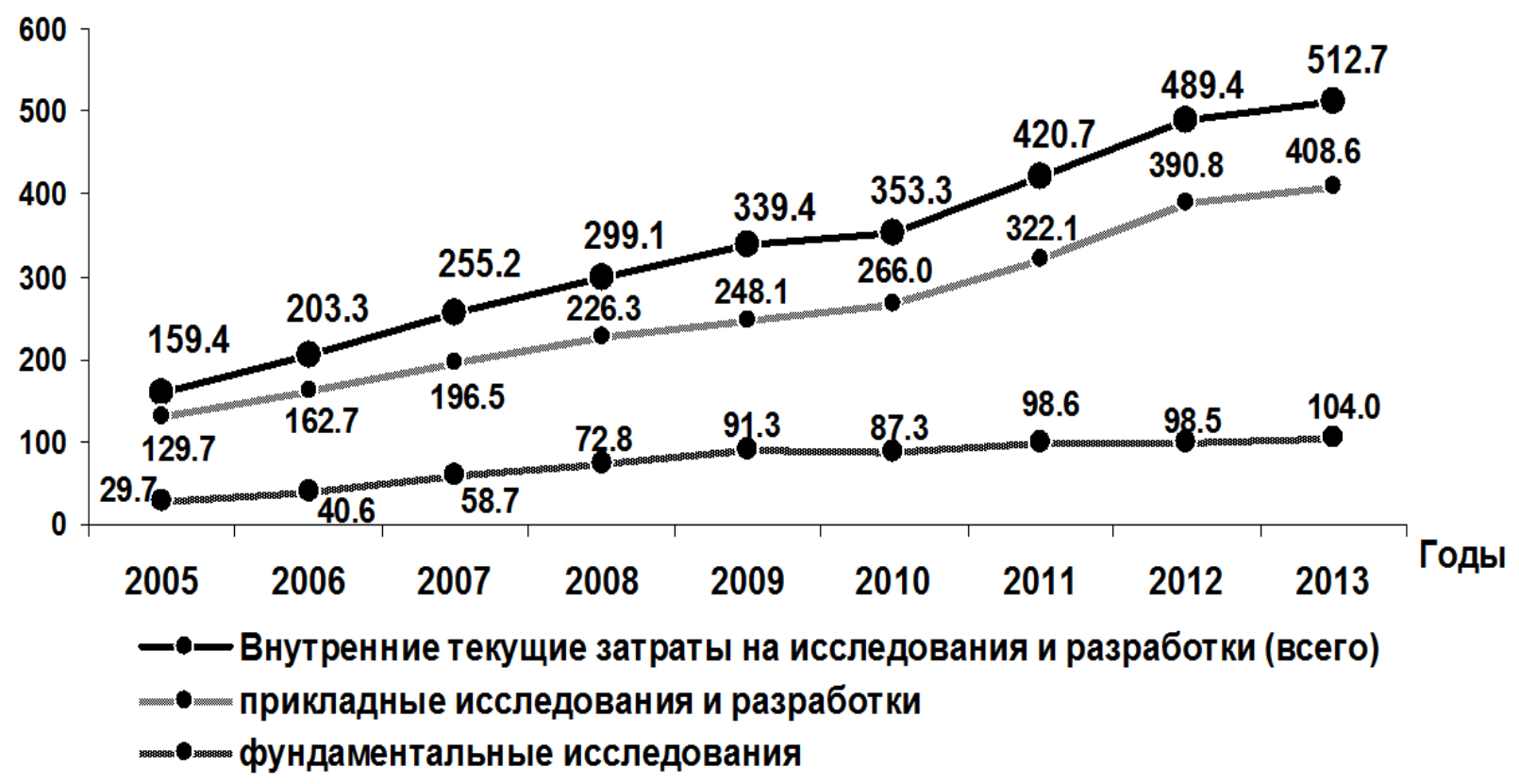

Рис. 6

Источник: составлено автором по данньлм официальных сайтов ФГБНУ НИИ РИНКЦЭ: http://www-old.extech.ru/, http://csrs.ru/ 


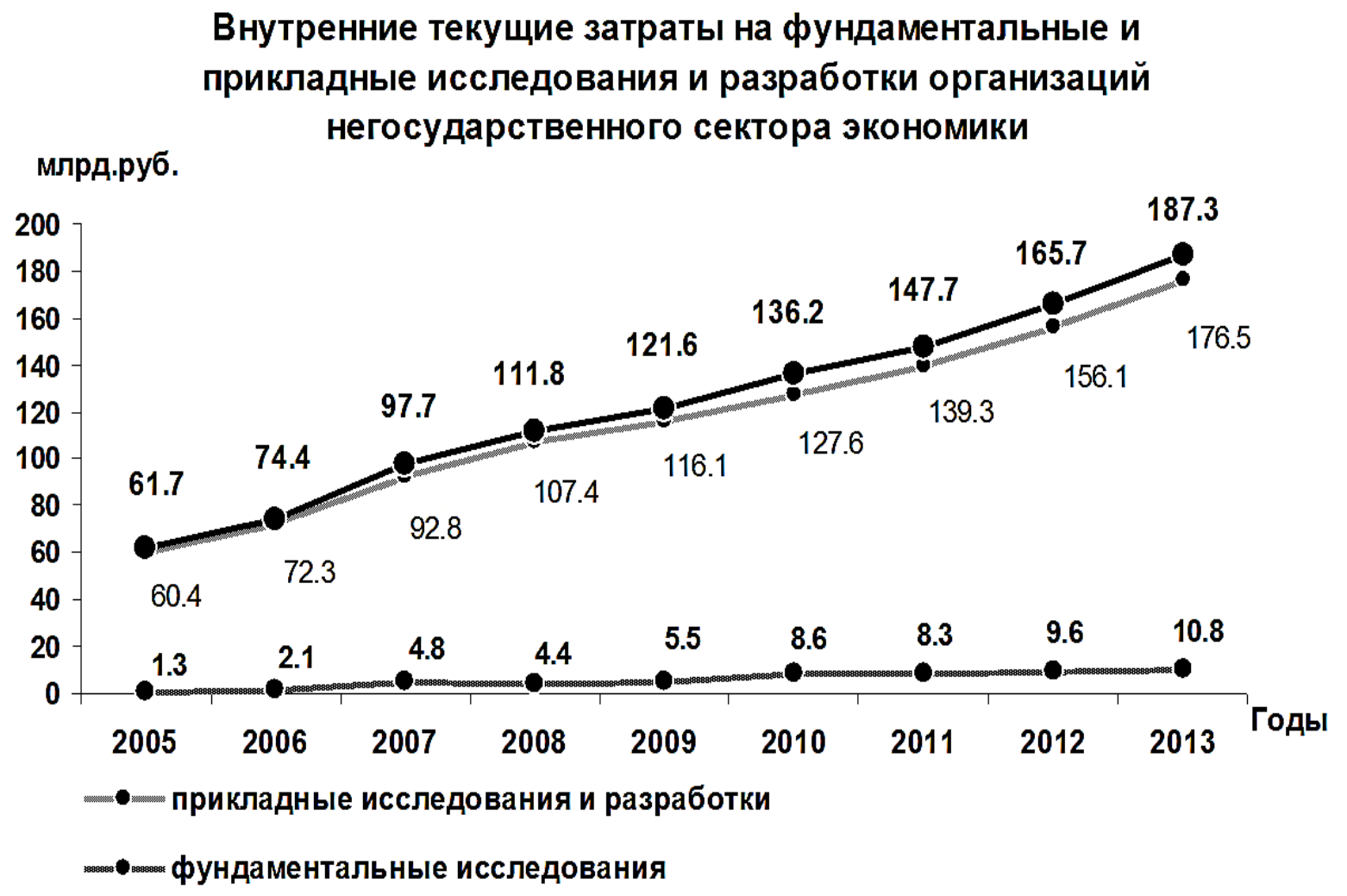

Рис. 7

Источник: составлено автором по данным официальньхх сайтов ФГБНУ НИИ РИНКЦЭ: http://www-old.extech.ru/, http://csrs.ru/

Как показывают данные приведенных графиков, рост затрат на исследования и разработки в рассматриваемом периоде можно считать весьма существенным. Так, в 2013 г. по сравнению с 2005 г. в сопоставимых ценах он составил по фундаментальным исследованиям $147,1 \%$, а по прикладным исследованиям 172,2\% [12, с. 96-100]. Последнее подчеркивает особую практическую значимость прикладных исследований для развития народного хозяйства. Однако важно отметить, что за тот же период темп роста затрат на фундаментальные исследования в организациях, не относящихся к государственному сектору экономики, был почти в три раза выше $(355,6 \%)$.

Данные показатели, позволяют говорить о возрастающем интересе негосударственных компаний к фундаментальной науке и постепенной переориентации с финансирования только текущих научно-технологических запросов на 
фундаментальные исследования, которые могут позволить осуществить определенный прорыв и конкурентные преимущества в будущем. Однако в абсолютном выражении внутренние затраты на фундаментальные исследования организаций негосударственного сектора достаточно скромные и составляли в 2013 г. 10,8 млрд руб. против 104,0 млрд руб. в государственном секторе, что вызывает потребность их существенного увеличения.

Следует отметить, что в целом по организациям государственного сектора экономики, занятым научными исследованиями и разработками, внутренние текущие затраты на разработки, приходящиеся на один рубль прикладных исследований, в рассматриваемом периоде снизились с 3,43 рубля в 2005 г. до 2,41 рубля в 2013 г. По оценкам специалистов, это отражает негативную тенденцию снижения практической результативности научной деятельности в стране. В то же время, по негосударственным организациям указанные затраты возросли с 7,5 рубля в 2005 г. до 11,6 рубля в 2013 г. Это указывает не только на более высокую результативность проводимых прикладных научных исследований в организациях, не относящихся к государственному сектору экономики, но и на более интенсивное использование результатов прикладных научных исследований в разработках.

Что касается такого важного показателя, как оплата труда в научной сфере, то удельный вес затрат на оплату труда работников, выполняющих научные исследования и разработки (без совместителей и лиц, работавших по договорам гражданско-правового характера) во внутренних текущих затратах исследовательских организаций государственного сектора экономики ежегодно увеличивался и достиг 43,1\% в 2013 г. против 39,0\% в 2005 г. Данная тенденция в перспективе должна положительно сказаться на эффективности научных исследований и разработок, Однако в настоящее время, как было отмечено ранее, рост затрат на науку не сопровождается аналогичным ростом ее результативности.

Основные средства, задействованные в проведении исследований и разработок в организациях государственного сектора экономики, составляли в 2013 г. в совокупности более $80 \%$ материально-технической базы научных организаций 
нашей страны. В основном они были сконцентрированы в Центральном федеральном округе (54,0\% всех основных средств научных организаций госсектора экономики), Северо-Западном - 12,4\%, Приволжском - 9,6\%, Сибирском - 8,9\%, Уральского - (7,3\%). Доля основных средств Южного $(3,3 \%)$, Дальневосточного $(2,6 \%)$ и Северо-Кавказского (2,1\%) федеральных округов по итогам 2013 г. была гораздо менее значительна.

Структура научного персонала организаций государственного сектора экономики имеет следующую специфику. Среди общего числа сотрудников преобладающее количество персонала работает в организациях, относящихся к экономическому виду деятельности «Научные исследования и разработки» (по итогам 2013 г. - 85,2\%). В образовательных организациях было занято 9,7\%, а в организациях производственного сектора (вид деятельности - «Промышленное производство») - 2,1\% научного персонала. В целом, сотрудники, занятые в научных организациях, учебных заведениях, и на предприятиях промышленности в общей сложности составляют порядка 97,0\% общей численности научного персонала организаций государственного сектора экономики. Приведенные данные свидетельствуют о недостаточном развитии научных исследований в образовательных организациях и производственном секторе, что затрудняет связь науки с производством, а также недостаточно задействует в научно - исследовательской работе квалифицированные кадры преподавательского состава.

Величина внутренних затрат, приходящихся на единицу численности персонала, занятого исследованиями и разработками, в государственном секторе экономики по состоянию на конец 2013 г. составила 1006,4 тыс. руб./чел. Выше среднего уровня этот показатель был в организациях, относящихся к виду экономической деятельности «Образование» (1203,8 тыс. руб./чел.). В современных условиях, однако, данный уровень затрат на персонал, осуществляющий научные исследования и разработки, не обеспечивает необходимого воздействия на качество и эффективность научной деятельности, что требует принятия более эффективных мер для стимулирования ее результативности. 
Важным индикатором, характеризующим в целом уровень научной деятельности, является ее эффективность, которая оценивается соотношением таких показателей, как число выполненных научных работ, публикаций и ссылок на них, суммарное количество выданных патентов заявителям, объем произведенной инновационной продукции с показателями, характеризующими внутренние затраты на научные исследования и разработки [5, с. 38]

К сожалению, в Российской Федерации показатели эффективности научных исследований и разработок имеют тенденцию к снижению. Так, за период с 2001 г. по 2011 г. эффективность упала почти на 45\%. В значительной мере это обусловлено существенно меньшим ростом ряда результирующих показателей в сравнении с увеличением внутренних затрат на исследования и разработки. Так, суммарное число международных патентов (триады и РСТ) увеличилось за указанный период примерно на 70\%, число публикаций практически не изменилось, а число ссылок на публикации увеличилось примерно на $23 \%$ при общем увеличении внутренних затрат в 2,8 раза [2, с. 33].

Таким образом, рост в последние годы финансирования фундаментальных исследований, прикладных исследований и разработок сопровождался снижением эффективности их использования, что вызывает потребность в совершенствовании организации этой деятельности по всей цепочке научных исследований и разработок.

Результативность научной деятельности реализуется в практических экономических результатах через систему инноваций. В целом затраты организаций государственного сектора экономики на технологические инновации в Российской Федерации постоянно возрастают. В 2013 г. они составили 359,3 млрд рублей, что в 2,3 раза больше аналогичного показателя 2010 г. А за период 20052013 гг. общий объем средств, направляемых на инновации в госсекторе вырос практически в 17 раз. 


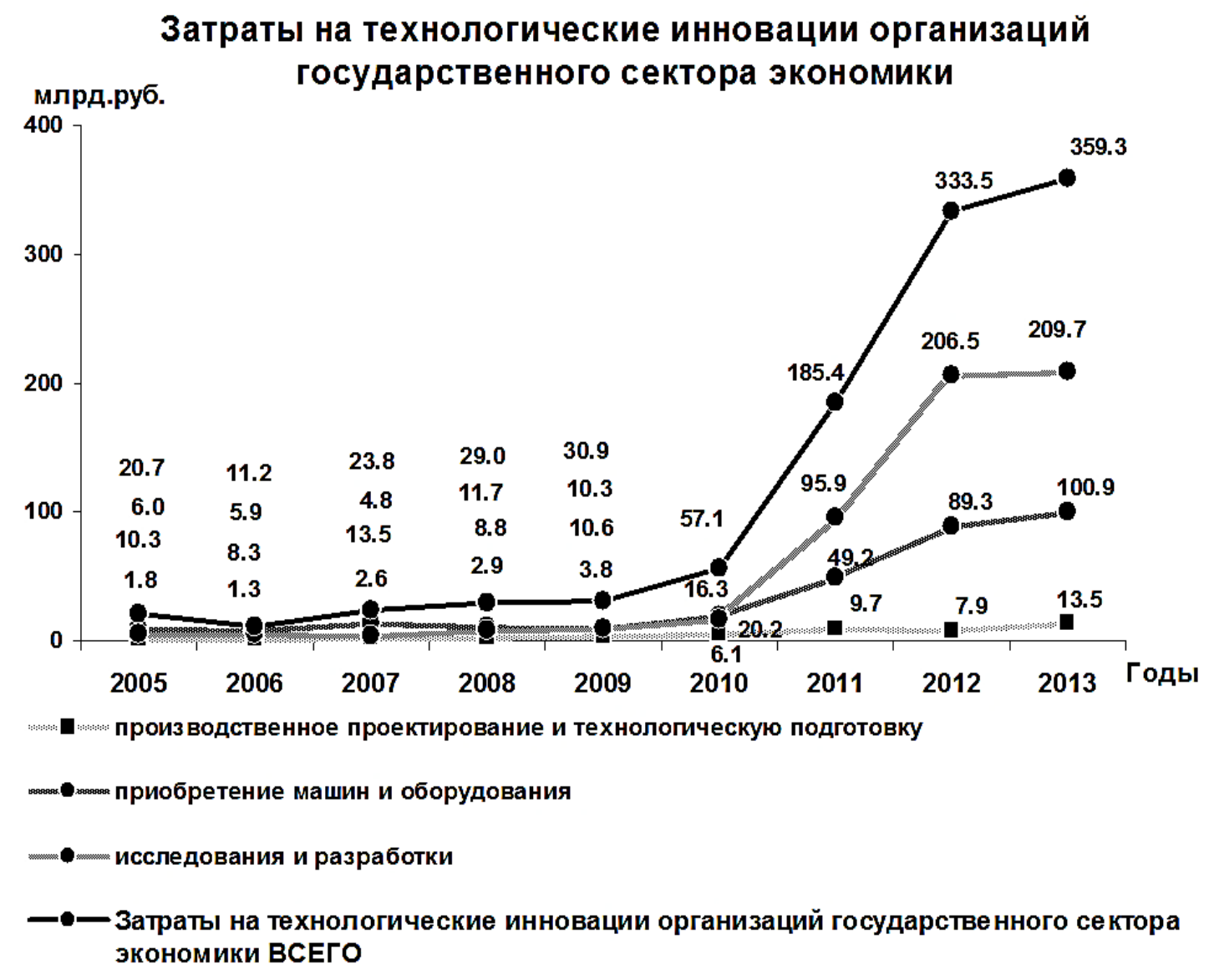

Рис. 8

Источник: составлено автором по данным официальных сайтов ФГБНУ НИИ РИНКЦЭ: http://www-old.extech.ru/, http://csrs.ru/

Что касается эффективности инновационной деятельности в России, то за рассматриваемый период она была достаточно скромной и уменьшилась за период 2005-2013 гг. примерно на 20\%. Это снижение произошло несмотря на рост результирующих показателей (доходность, определяемая по технологии баланса платежей; доля фармацевтического и аэрокосмического рынков; доля рынка компьютерной техники, электроники и оптики; объем экспорта фармацевтической продукции, компьютерной техники, электроники, оптики и продукции аэрокосмического назначения) за тот же период [2, с. 36]. Однако увеличение результирующих показателей инновационной деятельности происходило более медленными темпами, чем рост бюджетных расходов на эти цели, что и обусловило общее снижение эффективности инновационной деятельности в России в анализируемом периоде. 
Таким образом, анализ статистических данных о состоянии и развитии научных организаций академического сектора науки и государственного сектора экономики в целом за последние 13 лет, предшествующие реформе РАН, свидетельствует о существенных недостатках, накопившихся к этому периоду в организации научной, научно - технической и инновационной деятельности и необходимости реформирования как академического сектора науки, так и других ее секторов, а также необходимости совершенствования организации системы практического использования результатов научной, научно - технической и инновационной деятельности в социально - экономической сфере страны.

\section{Список литературы}

1. Глисин А.Ф. Некоторые особенности развития современной инновационной экономики // Сборник статей международной научно-практической конференции «Актуальные проблемы экономики». Часть 1 / Отв. ред. А.А. Сукиасян // Аэтерна. - Уфа, 2015. - С. 92-98.

2. Глисин Ф.Ф. Оценка эффективности научной и инновационной деятельности в зарубежных странах и в России // Инновации / В.В. Глисин, Ф.Ф. Калюжный. - 2015. - №6. - С. 32-37.

3. Основные показатели развития научных организаций, входящих в систему государственных академий наук: Информационно-статистические материалы, 2015 // Федеральное государственное бюджетное научное учреждение «Научно-исследовательский институт - Республиканский исследовательский научно-консультационный центр экспертизы» (ФГБНУ НИИ РИНКЦЭ).М.: ФГБНУ НИИ РИНКЦЭ. - 2015 [Электронный ресурс]. - Режим доступа: http://csrs.ru/archive/stat_2015_academy/

4. Выступление президента РАН академика Владимира Фортова на заседании Совета по науке и образованию 25.06.2015 / Реорганизация Российской академии наук. - 2013 [Электронный ресурс]. - Режим доступа: http://www.saveras.ru/archives/11353

5. Глисин Ф.Ф. Прогнозирование показателей научной деятельности // Инновации / Ф.Ф. Глисин, В.В. Калюжный. - 2014. - №11 (193). - С. 37-44. 
6. Федеральный закон от 20.07.1995 №115-Ф3 «О государственном прогнозировании и программах социально-экономического развития Российской Федерации» (с изменениями, внесенными Ф3 от 09.07.1999 №159-Ф3) / Консультант Плюс. - 1992-2015 [Электронный ресурс]. - Режим доступа: http://www.consultant.ru/document/cons_doc_LAW_7264

7. Постановление Правительства РФ от 04.01.1999 №1 «О прогнозе развития государственного сектора экономики Российской Федерации» (в редакции Постановления Правительства РФ от 30.12.2002 №939) // Консультант Плюс. 1992-2015 [Электронный ресурс]. - Режим доступа: http://www.consultant.ru/document/cons_doc_LAW_21472

8. Постановление Правительства РФ от 15.04.2014 №301 «Об утверждении государственной программы Российской Федерации «Развитие науки и технологий» на 2013-2020 годы» // Российская Газета [Электронный ресурс]. - Режим доступа: http://www.rg.ru/2014/04/24/texnologii-site-dok.html

9. Федеральный закон от 27.09.2013 №253-Ф3 «О Российской академии наук, реорганизации государственных академий наук и внесении изменений в отдельные законодательные акты Российской Федерации» // Консультант Плюс. - 1992-2015 [Электронный ресурс]. - Режим доступа: http://www.consultant.ru/document/cons_doc_LAW_152351

10. Постановление Правительства Российской Федерации от 25.10.2013 №959 «О федеральном агентстве научных организаций» // Российская Газета [Электронный ресурс]. - Режим доступа: http://www.rg.ru/2013/11/04/fano-sitedok.html

11. Указ Президента Российской Федерации от 27.09.2013 №735 «О Федеральном агентстве научных организаций» // Российская Газета [Электронный ресурс]. - Режим доступа: http://www.rg.ru/2013/09/27/fano-site-dok.html

12. Развитие научных организаций, входящих в государственный сектор экономики: Информационно-статистические материалы, 2015 / Федеральное государственное бюджетное научное учреждение «Научно-исследовательский институт - Республиканский исследовательский научно-консультационный 
центр экспертизы» (ФГБНУ НИИ РИНКЦЭ). - М.: ФГБНУ НИИ РИНКЦЭ, 2015 [Электронный ресурс]. - Режим доступа: http://csrs.ru/archive/stat_2015_gossector

13. Заседание Совета по науке и образованию 21 января 2016 г. Стенограмма. Дата опубликования 24.01.2016. Отдел редакции официального сайта Президента России, Москва, Кремль. - 2016 [Электронный ресурс]. - Режим доступа: http://www.kremlin.ru/events/president/news/51190

14. Медведев Д. Социально-экономическое развитие России: обретение новой динамики // Вопросы экономики. - 2016. - №10. - С. 4-39.

15. Ясин Е.Г. Состоится ли новая модель экономического роста в России? // Вопросы экономики / Е.Г. Ясин Н. Акиндинова. - 2013. - №5. - С. 5-16.

16. Проект Стратегии НТР России до 2035 года (Стратегия научно-технологического развития Российской Федерации на долгосрочный период) [Электронный ресурс]. - Режим доступа: http://sntr-rf.ru/

17. Иванов В.В. Проблемы научно-технологического развития России в контексте промышленной революции // Инновации. - 2016. - №6. - С. 3-8.

Глисин Алексей Федорович - канд. экон. наук, доцент кафедры оценки и управления собственностью ФГБОУ ВО «Финансовый университет при Правительстве Российской Федерации». Россия, Москва.

Glisin Alexey Fedorovich - candidate of economic sciences, associate professor of the department of property valuation and management FSBEI of HE "Financial University under the Government of the Russian Federation", Russia, Moscow. 